\title{
Utility of procalcitonin in a medical intensive care unit in Croatia
}

\author{
Ana Vujaklija Brajković (D) - Iva Košuta • Dora Tomek • Mia Rora • Jakša Babel • Dunja Rogić · Ana Lončar Vrančić • \\ Radovan Radonić
}

Received: 23 May 2020 / Accepted: 7 September 2020 / Published online: 6 October 2020

(C) Springer-Verlag GmbH Austria, part of Springer Nature 2020

\begin{abstract}
Summary
Aims To investigate the clinical benefit of routine procalcitonin (PCT) measurement in the medical intensive care unit (ICU) of a tertiary referral hospital.

Methods Adult patients with suspected infections were included. White blood cells, C-reactive protein (CRP), and PCT were measured.

Results In this study 129 patients of median age 64 years (interquartile range 39-89years) were prospectively included. The Acute Physiology And Chronic Health Evaluation II (APACHE II) and Sequential Organ Failure Assessment (SOFA) scores were $21 \pm 14$ and $7 \pm 6$, respectively. Intensive care unit (ICU) mortality was $22.5 \%$. Immunocompromised patients constituted $39.5 \%$. A significant correlation was observed between PCT and APACHE II (Spearman's rho $0.461, p<0.01$ ), PCT and SOFA (Spearman's rho 0.494, $p<0.01$ ) and PCT and CRP (Spearman's rho $0.403, p<0.01)$. Most patients $(n=83,64.3 \%)$ received antibiotics before admission. No difference in PCT $(1.56 \pm 8 \mu \mathrm{g} / \mathrm{L}$ vs. $1.44 \pm 13 \mu \mathrm{g} / \mathrm{L}, p=0.6)$ was observed with respect to previous antibiotic therapy. Levels of PCT and CRP were significantly increased in patients with positive blood cultures, the
\end{abstract}

\footnotetext{
A. Vujaklija Brajković, M.D., PhD $(\bowtie) \cdot$ I. Košuta · M. Rora · J. Babel · R. Radonić

Department of Internal Diseases, Department of Intensive Care Medicine, University Hospital Centre Zagreb,

Kispaticeva 12, 10000 Zagreb, Croatia

avujaklija@gmail.com

\section{Tomek}

Department of Oncology and Radiotherapy, University

Hospital Centre Zagreb, Kispaticeva 12, 10000 Zagreb, Croatia

D. Rogić · A. Lončar Vrančić

Department of Laboratory Diagnostics, University Hospital Centre Zagreb, Kispaticeva 12, 10000 Zagreb, Croatia
}

infection caused by Gram-negative microorganism regardless of disease severity and pneumonia with complications. PCT did not differ among patients with positive vs negative urine culture $(4.6 \pm 16 \mu \mathrm{g} / \mathrm{L}$ vs. $1.76 \pm 11.9 \mu \mathrm{g} / \mathrm{L}$ ) or positive vs. negative endotracheal aspirate $(1.93 \pm 11.4 \mu \mathrm{g} / \mathrm{L}$ vs. $1.76 \pm 1.11 \mu \mathrm{g} / \mathrm{L})$. PCT-guided stewardship was applied in 36 patients (28\%).

Conclusion Increased initial PCT levels might point to the development of more severe disease caused by Gram-negative bacteria, regardless of previous antibiotic treatment. The results pertain to immunocompetent and immunocompromised patients. Implementation of PCT-guided stewardship in those patients is possible and relies on experience as well as knowledge of reference change value for a marker within the specific setting.

Keywords Biomarker - Procalcitonin - Sepsis · Pneumonia $\cdot$ Critical illness

\section{Introduction}

Sepsis is a medical emergency and rapid initiation of antimicrobial therapy is of utmost importance [1]; however, up to $30-50 \%$ of prescribed antibiotics may be unnecessary [2]. Antibiotic overprescription can lead to the emergence of antibiotic-resistant bacterial strains, unnecessary drug adverse events, antibiotic-related colitis, etc. Therefore, antibiotic stewardship and resistance problems are very important in the critical care setting. Biomarkers might provide additional rationale to initiate, withhold, or stop the antibiotic administration. Procalcitonin is probably the most widely studied rapidly available biomarker with the potential to guide antibiotic prescription in patients with infections. In the critical care setting, published studies differ greatly considering patient 
case mix [3-7], the source of infection [3, 4, 6-13], the severity of the disease $[4,5,10-12,14]$, exclusion criteria as well as cut-offs and laboratory methods for PCT measurements [3, 11, 13-15]. Studies so far have shown that PCT -guided antimicrobial stewardship regarding discontinuation of antimicrobial therapy is safe, primarily by demonstrating that patients who received antibiotic therapy guided by PCT levels had similar mortality to patients who were receiving antibiotic therapy according to standard guidelines [16-18]. Moreover, PCT-guided therapy showed a clear trend toward the reduction of antibiotic consumption $[3,5,6,8,9,12-14]$, which might reduce healthcare expenditure and decrease the development of antimicrobial resistance. Even high-risk patient groups, such as immunocompromised and cancer patients, have been shown to benefit from shorter antibiotic treatment [19].

An international expert consensus on PCT-guided antibiotic stewardship proposed an algorithm for PCT use in critically ill patients [18]. The protocol incorporates PCT results in clinical assessment and suggests discontinuation of antibiotics if PCT $<0.5 \mu \mathrm{g} / \mathrm{L}$ or if a reduction of PCT by more than $80 \%$ is present regardless of the source of infection. The role of PCT in the initiation of empirical antibiotic therapy in severely ill patients is still to be defined. Clinical judgment is currently the most important, and diagnostic tests, including biomarkers, might provide added value.

PCT testing was implemented in the emergency laboratory of the department of laboratory diagnostics in October 2016. As an initial management strategy, only the emergency department and all intensive care units gained unlimited access to direct test ordering through the hospital information system, all other wards were instructed to contact the laboratory before test ordering.

The primary endpoint of our research was to investigate the clinical applicability of routine PCT measurement in the medical ICU within the tertiary referral hospital, particularly with respect to antibiotic stewardship.

Secondary endpoints were to analyze the correlation of PCT with disease severity and source of infection, as well as the applicability of PCT in immunocompromised patients with a suspected infection.

\section{Material and methods}

This was an epidemiological prospective single center study carried out in the medical ICU at the University Hospital Centre Zagreb, Croatia.

Consecutive series of patients hospitalized from 1 January 2018 to 31 December 2018 were included in the study.

Inclusion criteria were critically ill adult patients ( $\geq 18$ years old) with suspected infection. Immunocompetent and immunocompromised patients were included. The immunocompromised patient is defined as one in whom any aspect of host defense is deficient.

The suspected infection was defined to involve a patient who had one or several clinical symptoms of infection (fever, tachycardia, tachypnea, cough, dysuria), inflammatory markers and microbiological cultures were requested by attending physicians, and empirical antibiotic therapy was initiated.

Patients admitted due to the noninfective causes were excluded from the study.

Sepsis and septic shock were defined according to the Third International Consensus Definitions for Sepsis and Septic Shock (Sepsis-3) [20].

Acute kidney injury (AKI) was defined according to the KDIGO 2012 criteria as follows: 1) increase in serum creatinine (SCr) by $\geq 0.3 \mathrm{mg} / \mathrm{dl}(\geq 26.5 \mu \mathrm{mol} / \mathrm{l})$ within $48 \mathrm{~h}$ or 2 ) increase in SCr to $\geq 1.5$ times baseline, which is known or presumed to have occurred within the prior 7 days or urine volume $<0.5 \mathrm{ml} / \mathrm{kg} / \mathrm{h}$ for $6 \mathrm{~h}$ [21].

The Acute Physiology And Chronic Health Evaluation II (APACHE II) [22] and Sequential Organ Failure Assessment (SOFA) [23] scores are routinely used in a critical care setting to assess organ dysfunction and/or predict mortality.

Inflammatory markers measured at admission were white blood cells (WBC), C-reactive protein (CRP), and procalcitonin (PCT). All tests were performed in the hospital department of laboratory diagnostics.

PCT testing was performed using Elecsys Brahms automated chemiluminescence immunoassay applied to Roche Cobas CE 6000 system (Roche Diagnostics, Basel, Switzerland). Analytical sensitivity (detection limit) of the test is $0.02 \mu \mathrm{g} / \mathrm{L}$, while functional sensitivity (quantification limit) defined as the coefficient of variation $<20 \%$ is $0.06 \mu \mathrm{g} / \mathrm{L}$. Test result interpretation guidance according to risk categories with respect to PCT $(\mu \mathrm{g} / \mathrm{L})$ values was provided by our laboratory as follows: 1) PCT $<0.5 \mu \mathrm{g} / \mathrm{L}$ low risk of systemic bacterial or fungal infection, 2) PCT 0.5-2.0 $\mu \mathrm{g} / \mathrm{L}$ substantial risk of systemic bacterial or fungal infection, 3) PCT 2.0-10 $\mu \mathrm{g} / \mathrm{L}$ high risk of sepsis and progression to septic shock, PCT $>10 \mu \mathrm{g} / \mathrm{L}$ high risk of septic shock [24]. The laboratory set turnaround time for test results was $60 \mathrm{~min}$. According to available guidelines, minimum PCT retesting interval was set within the hospital laboratory order entry system at $24 \mathrm{~h}$ [25].

The positivity of blood cultures depended on the isolated microorganism. The following microorganisms were considered as skin contaminants: nonStaphylococcus aureus Staphylococci (e.g., coagulasenegative Staphylococci, Staphylococcus haemoliticus, Staphylococcus intermedius, Staphylococcus capitis, etc), Corynebacterium species, Bacillus species, Propionibacterium species and Micrococcus species.

All data were analyzed using SPSS for Windows, version 23.0 (SPSS Inc, Chicago, IL, USA). Numeri- 
cal data were analyzed for homogeneity using Kolmogorov-Smirnov and Shapiro-Wilk tests. Normally distributed data were expressed as means and standard deviation (SD), non-normally distributed data as median with interquartile range (IQR). The Student's t-test was used when comparing mean values and Mann-Whitney U-test when comparing medians. Categorical data comparison was carried out using the $\chi^{2}$ test. A $p$-value $<0.05$ was considered statistically significant.

The Ethics Committee of the University Hospital Centre Zagreb approved this research as a non-sponsored prospective epidemiological study. Considering the design of the study and possible exceptions to the rule of informed consent [26], the informed consent was waived for the present study.

Table 1 Baseline demographics and inflammatory markers at admission. Values are medians with interquartile ranges

\begin{tabular}{|c|c|}
\hline & $\begin{array}{l}\text { All patients } \\
(N=129)\end{array}$ \\
\hline Age (years) & $64 \pm 25$ \\
\hline Male gender, $n(\%)$ & $83(63.6)$ \\
\hline \multicolumn{2}{|l|}{ Admission diagnoses } \\
\hline Sepsis, $n(\%)$ & $51(39.5)$ \\
\hline Pneumonia, $n(\%)$ & $38(29.5)$ \\
\hline Pancreatitis, $n(\%)$ & $6(4.6)$ \\
\hline Other, $n(\%)$ & $34(26.4)$ \\
\hline \multicolumn{2}{|l|}{ Comorbidities } \\
\hline Diabetes, $n(\%)$ & $28(21.7)$ \\
\hline Hypertension, $n(\%)$ & $44(34.1)$ \\
\hline Chronic renal failure & $21(16.2)$ \\
\hline Chronic hemodialysis & 14 (10.8) \\
\hline Hematologic malignancy & $35(27.1)$ \\
\hline Autoimmune disease & $10(7.8)$ \\
\hline Neoplasm, solid & $7(5.4)$ \\
\hline Transplantation of solid organ, previously & $5(3.9)$ \\
\hline APACHE II & $21 \pm 14$ \\
\hline SOFA & $7 \pm 6$ \\
\hline SOFA $>2, n(\%)$ & $120(93)$ \\
\hline Neutropenic patients, $n(\%)$ & $22(17.1)$ \\
\hline Immunocompromised patients, $n(\%)$ & $51(39.5)$ \\
\hline Recent chemotherapy, $n(\%)$ & $28(21.7)$ \\
\hline PCT, entire cohort $(\mu \mathrm{g} / \mathrm{L})$ & $1.66 \pm 11.43$ \\
\hline PCT, without previous $\mathrm{AB}(\mu \mathrm{g} / \mathrm{L})$ & $1.56 \pm 8^{\mathrm{NS}}$ \\
\hline PCT, with previous $A B(\mu g / L)$ & $1.44 \pm 13^{\mathrm{NS}}$ \\
\hline CRP, entire cohort (mg/L) & $102 \pm 166$ \\
\hline CRP, without previous $A B$ (mg/L) & $127 \pm 171^{\text {NS }}$ \\
\hline CRP, with previous $A B(\mathrm{mg} / \mathrm{L})$ & $98 \pm 137^{N S}$ \\
\hline WBC $\left(10^{9} / \mathrm{L}\right)$ & $L 11.6 \pm 9.5$ \\
\hline \multicolumn{2}{|c|}{$\begin{array}{l}\text { APACHE II Acute Physiology And Chronic Health Evaluation II, SOFA Sequen- } \\
\text { tial Organ Failure Assessment, } P C T \text { procalcitonin, CRPC-reactive protein, } \\
\text { WBC white blood cells, } A B \text { antibiotic therapy, Other cardiac decompen- } \\
\text { sation, cardiac arrest, pulmonary embolism, local infection, Hematologic } \\
\text { malignancy leukemia, lymphoma, NS not statistically significant } \\
\text { *Statistically significant, } p<0.05\end{array}$} \\
\hline
\end{tabular}

\section{Results}

In the reporting period, 619 patients were hospitalized in the medical ICU, out of which 129 (20.8\%) had suspected infection. The median age was 64 years (39-89years) with $63.6 \%$ male patients. Sepsis and pneumonia were the most common admission diagnoses. Immunocompromised patients constituted $39.5 \%$ of the included patients (Table 1). Mechanical ventilation was administered in 65 patients (50.4\%), 38 patients $(29.5 \%)$ received vasoactive therapy, 54 patients (42\%) developed AKI, of which 18 (33\%) received renal replacement therapy (RRT). The median ICU length of stay (ICU LOS) was 10 (2-18) days and 100 patients $(77.5 \%)$ were discharged from ICU alive.

Table 2 Microorganisms isolated from blood cultures, urine cultures and endotracheal aspirates

\begin{tabular}{|c|c|c|}
\hline & Microorganism & N \\
\hline \multirow{12}{*}{$\begin{array}{l}\text { Blood } \\
\text { cul- } \\
\text { ture }\end{array}$} & Escherichia coli & 8 \\
\hline & Pseudomonas aeruginosa & 8 \\
\hline & Acinetobacter baumannii & 7 \\
\hline & Klebsiella pneumoniae & 4 \\
\hline & Haemophilus influenzae & 2 \\
\hline & Raoultella species & 2 \\
\hline & Enterococcus faecium and Enterococcus faecalis & 6 \\
\hline & Staphylococcus species ${ }^{\mathrm{a}}$ & 3 \\
\hline & Methicillin-resistant Staphylococcus aureus & 2 \\
\hline & Staphylococcus hominis ${ }^{\mathrm{a}}$ & 2 \\
\hline & Staphylococcus aureus & 1 \\
\hline & Clostridium perfringens & 1 \\
\hline \multirow{7}{*}{$\begin{array}{l}\text { Urine } \\
\text { cul- } \\
\text { ture }\end{array}$} & Escherichia coli & 9 \\
\hline & Pseudomonas aeruginosa & 8 \\
\hline & Klebsiella pneumoniae & 4 \\
\hline & Enterobacter species & 2 \\
\hline & Morganella morganii & 1 \\
\hline & Acinetobacter baumannii & 1 \\
\hline & Enterococcus faecalis & 7 \\
\hline \multirow{13}{*}{$\begin{array}{l}\text { Endo- } \\
\text { tra- } \\
\text { cheal } \\
\text { aspi- } \\
\text { rate }\end{array}$} & Pseudomonas aeruginosa & 14 \\
\hline & Klebsiella pneumoniae & 10 \\
\hline & Acinetobacter baumannii & 6 \\
\hline & Stenotrophomonas maltophilia & 4 \\
\hline & Enterobacter cloacae & 3 \\
\hline & Serratia marcescens & 1 \\
\hline & Haemophilus influenzae & 1 \\
\hline & Citrobacter freundii & 1 \\
\hline & Streptococcus species & 8 \\
\hline & Enterococcus faecalis and Enterococcus faecium & 6 \\
\hline & Staphylococcus aureus & 4 \\
\hline & Staphylococcus species & 3 \\
\hline & Methicillin-resistant Staphylococcus aureus & 3 \\
\hline
\end{tabular}



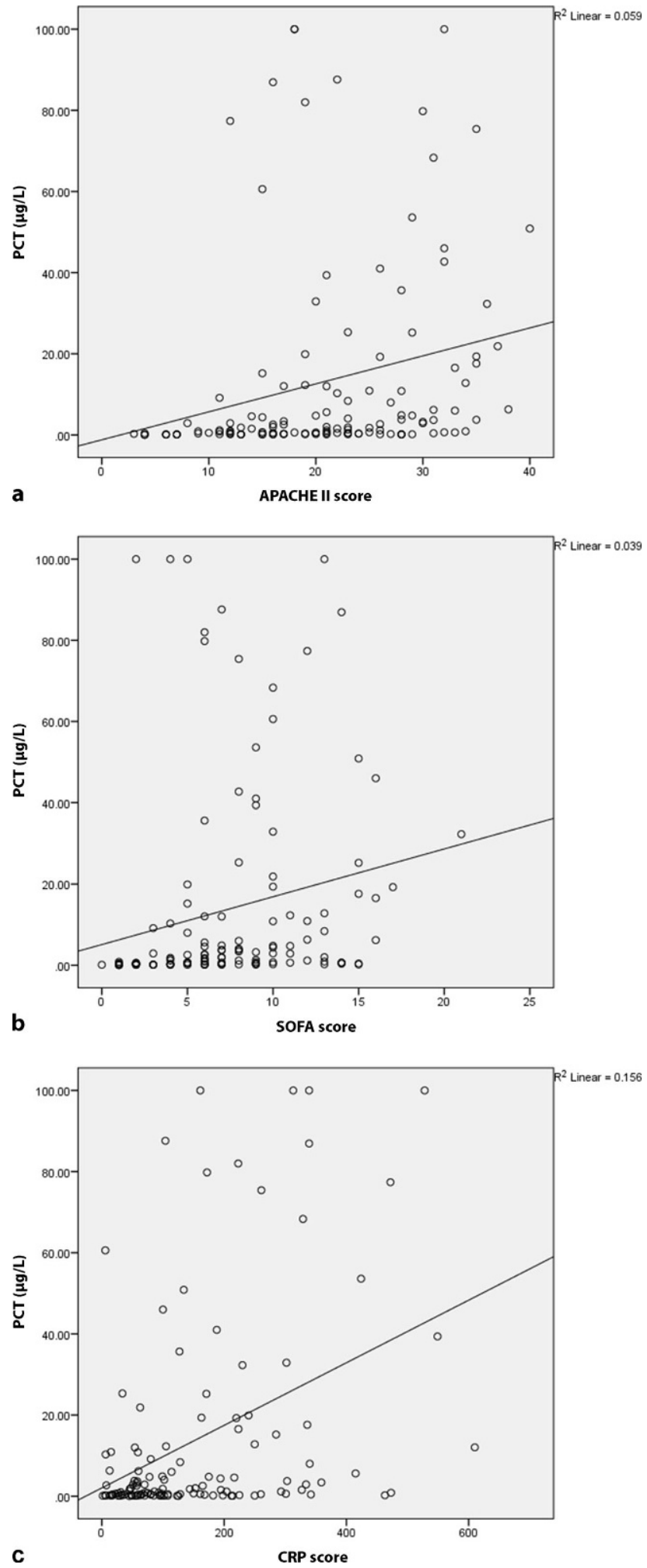

Fig. 1 a Correlation among PCT $(\mu \mathrm{g} / \mathrm{L})$ and APACHE II (Spearman's rho $0.461, p<0.01$ ), b correlation among PCT $(\mu \mathrm{g} / \mathrm{L})$ and SOFA (Spearman's rho $0.494, p<0.01)$ and $c$ correlation among PCT $(\mu \mathrm{g} / \mathrm{L})$ and CRP $(\mathrm{mg} / \mathrm{L})$ (Spearman's rho $0.403, p<0.01)$
Pneumonia was the most frequent infection (87 patients, $67.4 \%)$, followed by intra-abdominal infections (13 patients, $10 \%$ ), and urinary tract infections (10 patients, $7.8 \%), 16$ patients $(14.8 \%)$ had another source of infection (endocarditis, soft tissue, bone). Microbiological cultures were positive in $86(66.7 \%)$ patients. Gram-negative microorganisms predominated in all microbiological specimens (Table 2).

A significant correlation was observed among PCT and APACHE II, PCT and SOFA and PCT and CRP (Fig. 1). No correlation was detected between CRP and APACHE II ( $\mathrm{r}=0.05, p=0.55)$, CRP and SOFA $(\mathrm{r}=-0.004$ $p=0.9625)$, WBC and APACHE II $(\mathrm{r}=-0.015, p=0.87)$, WBC and SOFA ( $\mathrm{r}=-0.12, p=0.18)$.

Inflammatory markers for the entire cohort at admission are presented in Table 1.

Most patients $(83,64.3 \%)$ received antibiotics before admission. No difference in PCT nor CRP was observed concerning previous antibiotic therapy (Table 1).

The PCT and CRP levels were significantly increased in patients with positive blood cultures, the infection caused by Gram-negative microorganism regardless of disease severity (no difference in SOFA and APACHE II scores), and pneumonia with complications (Table 3). PCT did not differ among patients with positive vs. negative urine culture or positive vs. negative endotracheal aspirate (Table 4). Patients with positive endotracheal aspirates had significantly higher APACHE II and SOFA scores than patients without isolated microorganisms from the endotracheal aspirate.

Median time from ICU admission to PCT testing was 1 day ( $1 \pm 2$ days), and control PCT was ordered 2 days later ( $2 \pm 3$ days). Antimicrobial treatment change based on PCT value was done in 36 patients $(28 \%)$. The antibiotic therapy was discontinued in 7 patients in whom control PCT was lower than $0.5 \mu \mathrm{g} / \mathrm{L}$ or a reduction of PCT by more than $80 \%$ was detected. None of the patients developed reinfections. For those 7 patients, antibiotic treatment was shortened for 1.5 days in comparison to standard protocol, and those patients were discharged from the ICU 1 day earlier in comparison to the standard of care. Patients in whom antibiotic therapy was discontinued $(n=7)$ based on PCT measurement had median ICU LOS of 6 days (2-10 days) and patients who continued antibiotic therapy $(n=119)$ had median ICU LOS of 8 days $(0-16$ days). The difference is not statistically significant $(p=0.442)$.

In the other 29 patients, the antimicrobial treatment was either escalated or de-escalated according to PCT results. Due to the increase of control PCT above reference change value $(60 \%$ change, data provided by our laboratory), the escalation of antimicrobial therapy was done in 19 patients. In patients who were clinically stable and had a decrease of PCT between $60 \%$ and $80 \%$, the antibiotic therapy was de-es- 
Table 3 Procalcitonin and C-reactive protein according to blood culture positivity and pneumonia with complications. Values are medians with interquartile ranges

\begin{tabular}{|c|c|c|c|c|c|c|c|c|}
\hline Variable & $\mathrm{BC}+$ & $\mathrm{BC}-$ & $\begin{array}{l}\mathrm{BC}+ \\
\mathrm{G}+\end{array}$ & $\begin{array}{l}\mathrm{BC}+ \\
\mathrm{G}-\end{array}$ & PNM, not complicated & $\begin{array}{l}\text { PNM, } \\
\text { with shock }\end{array}$ & $\begin{array}{l}\text { PNM, } \\
\text { BC- }\end{array}$ & $\begin{array}{l}\text { PNM, } \\
\mathrm{BC}+\end{array}$ \\
\hline$N$ & 46 & 61 & 15 & 31 & 46 & 29 & 35 & 40 \\
\hline PCT, $\mu \mathrm{g} / \mathrm{L}$ & $8.2(1-25.3)^{\star}$ & $\begin{array}{l}0.6 \\
(0.2-4.36)^{*}\end{array}$ & $\begin{array}{l}1.9 \\
(0.6-12.8)^{\star}\end{array}$ & $\begin{array}{l}15.9 \\
(3.5-59.1)^{\star}\end{array}$ & $1.1(0.4-3.7)^{\star}$ & $16.5(4.4-50.9)^{*}$ & $0.9(0.4-8)^{a}$ & $7.2(0.9-22.7)^{\mathrm{a}}$ \\
\hline $\mathrm{CRP}, \mathrm{mg} / \mathrm{L}$ & $\begin{array}{l}167 \\
(64-295)^{\star}\end{array}$ & $\begin{array}{l}86 \\
(51-169)^{*}\end{array}$ & $\begin{array}{l}139 \\
(32-261)^{\star \star}\end{array}$ & $\begin{array}{l}181 \\
(100-335)^{\star \star}\end{array}$ & $80(48-163)^{\star}$ & $194(122-328)^{\star}$ & $\begin{array}{l}108 \\
(55-195)^{\text {NS }}\end{array}$ & $143(53-267)^{\mathrm{NS}}$ \\
\hline
\end{tabular}

Table 4 Procalcitonin and C-reactive protein values according to urine culture and endotracheal aspirate. Values are medians with interquartile ranges

\begin{tabular}{|c|c|c|c|c|}
\hline & $U C+$ & UC - & ETA + & ETA - \\
\hline PCT $(\mu \mathrm{g} / \mathrm{L})$ & $\begin{array}{l}4.6 \\
(0.4-15.2)\end{array}$ & $\begin{array}{l}1.7 \\
(0.2-12.0)\end{array}$ & $\begin{array}{l}1.93 \\
(0.3-12.1)\end{array}$ & $\begin{array}{l}1.7 \\
(0.3-12.6)\end{array}$ \\
\hline $\mathrm{CRP}$ (mg/L) & $\begin{array}{l}134 \\
(57-216.6)\end{array}$ & $\begin{array}{l}104 \\
(52.2-223.2)\end{array}$ & 99 (56-188) & $\begin{array}{l}108 \\
(53.3-250)\end{array}$ \\
\hline APACHE II & $21(15-28)$ & 20 (14-28) & $23(17-29)^{*}$ & $19(12-25)^{\star}$ \\
\hline SOFA & $7(5-11)$ & $7(4-10)$ & $8(5-12)^{*}$ & $6(3-9)^{\star}$ \\
\hline \multicolumn{5}{|c|}{$\begin{array}{l}\text { PCT procalcitonin, CRP C reactive protein, UC urine culture, ETA endotra- } \\
\text { cheal aspirate, - negative, + positive, APACHE II Acute Physiology, And } \\
\text { Chronic Health Evaluation II, SOFA Sequential Organ Failure Assessment } \\
{ }^{*} \text { Statistically significant, } p<0.05\end{array}$} \\
\hline
\end{tabular}

calated according to microbiological isolates and susceptibility testing.

\section{Discussion}

The study presents the evaluation of PCT in severely ill medical patients in a tertiary teaching hospital in Croatia following the introduction of laboratory PCT test for intensive care units. The study included 129 consecutive patients with a suspected infection that required ICU admission.

The initial PCT value correlated with disease severity, including both APACHE II and SOFA scores, which was not the case with other inflammatory markers. We also showed a positive correlation between PCT and CRP, which is considered the most frequently used inflammatory biomarker. The advantages of PCT over CRP are a rapid value increase in bacterial infections (2-4h) [27] and relatively short half-life (22-30 h) accompanied by a rapidly declining level following the resolution of infection [28].

Most patients received antimicrobial therapy before the ICU admission; however, no difference in PCT $(1.56 \pm 8 \mu \mathrm{g} / \mathrm{L}$ vs. $1.44 \pm 13 \mu \mathrm{g} / \mathrm{L}, p=0.6)$ was observed with respect to previous antibiotic therapy. This finding might be explained by the fact that patients' condition deteriorated despite initiated antibiotic therapy, which suggests inadequate antimicrobial treatment and/or uncontrolled infection. The obtained results indicate that PCT is also a reliable marker in patients who were pretreated with antibiotics. This is important because most of the studies on PCT in crit- ical illness excluded patients who received antibiotic therapy for longer than $48 \mathrm{~h}$ prior to ICU admission $[3,6,8,11,13]$. One of the exceptions is the study by Stolz et al. on 101 patients with ventilator-associated pneumonia, in which $75 \%$ of the patients had received antibiotic before inclusion in the study and median PCT levels were similar in patients pretreated with antibiotics $(0.73 \mu \mathrm{g} / \mathrm{L})$ and in patients without antibiotic exposure $(0.72 \mu \mathrm{g} / \mathrm{L})$ [9]. In that study PCT measurement was done using a time-resolved amplified cryptate emission technology assay (Kryptor ${ }^{\circledR}$ PCT, Brahms AG, Hennigsdorf, Germany) which gives results comparable to the assay used in our study.

The PCT level depended on the site of infection, being the highest in patients with positive blood cultures $(8.2 \pm 24.1 \mu \mathrm{g} / \mathrm{L})$, lower in those with positive urine culture $(4.6 \pm 16 \mu \mathrm{g} / \mathrm{L})$, and the lowest in patients with the positive endotracheal aspirate $(1.93 \pm 11.4 \mu \mathrm{g} / \mathrm{L})$. Previous research also showed that PCT levels differ regarding the source of infection, being the highest in patients with positive blood cultures and the lowest in patients with positive endotracheal aspirates $[9,13$, 29]. Moreover, in the presented study patients with isolated Gram-negative bacteria in blood cultures had significantly higher PCT and CRP than patients who had documented bloodstream infections with Grampositive bacteria. Studies regarding PCT level and Gram-positive vs. Gram-negative infections provide contradictory results. While some studies found no difference between the baseline PCT levels and the PCT levels measured over time in patients with Grampositive versus Gram-negative infections [8], others claimed that PCT levels differentiate Gram-negative from Gram-positive bacterial and fungal sepsis [30, 31]. In the current study, PCT was also significantly elevated in patients who had pneumonia with complications. The possibility that elevated levels of PCT indicate a more severe disease caused by Gram-negative bacteria might be a useful information in everyday clinical practice.

The available evidence demonstrates that PCTguided antibiotic stewardship effectively reduces the total duration of antimicrobial therapy (antibiotic days), which ranges from $5 \%$ [14] to even $20-30 \%$ [3, $5,6,9,12]$; this reduction is accompanied by a reduction in antimicrobial costs $[6,12]$. A systematic review 
by Huang et al. determined that PCT-guided antibiotic discontinuation strategy resulted in fewer total days with antibiotics and longer antibiotic-free days. The antibiotic days decreased for 1.7 days and antibiotic-free days increased for approximately 2.3 days [16]. Wirz et al. showed that PCT-guided protocols moderately reduced antibiotics by approximately 1 day, 9.3 vs. 10.4 days; however, the effect was most pronounced in the subgroup of patients with skin/ soft tissue infections in which reduction of antibiotic duration was approximately 4 days [17]. The reduction in the duration of antimicrobial therapy might slow down the emergence of antimicrobial resistance and decrease healthcare costs. On the other hand, a Cochrane systematic review showed that PCT-guided protocols contribute to earlier administration of antibiotics [32], which might be beneficial in severely ill patients because every delay in timely treatment is associated with worse outcomes [1].

Even though PCT-guided algorithms are relatively simple, the adherence to protocols is usually low or moderate $[3,5,10,12,14]$; however, the adherence to protocols is higher in clinical centers that routinely use biomarkers in clinical assessment [4, 8, 9, 13] indicating that better acquaintance with the method might lead to more successful acceptance of protocols. In the current study, PCT-guided stewardship was successfully applied in 36 patients (28\%). The incomplete application of PCT-guided stewardship in our patient series could be partially explained by a lack of experience and confidence in the studied biomarker. In addition, PCT-guided stewardship has still not been extensively and adequately evaluated in infections caused by multidrug-resistant (MDR) microorganisms, which were isolated in a significant proportion of our patients.

The novelty presented in this study pertains to the patient case-mix, especially a high proportion of immunocompromised patients reaching almost $40 \%$ of the entire cohort. Previous studies found procalcitonin as a reliable diagnostic marker of bacteremia in febrile patients with malignancies [33-35]; however, the biomarker was not comprehensively investigated in critically ill immunocompromised patients. Bele et al. showed that increased PCT concentration $(>0.5 \mu \mathrm{g} / \mathrm{L})$ on the first day of the disease had $100 \%$ sensitivity and $63 \%$ specificity for diagnosing bacterial sepsis in critically ill immunocompromised patients, which implies that bacterial infections can be accurately ruled out if the threshold of $0.5 \mu \mathrm{g} / \mathrm{L}$ is not reached [32]. Our results indicate that PCT can predict the severity of the disease, source of infection, and possibly differentiate Gram-negative from Gram-positive sepsis in immunocompromised severely ill patients.

Another biomarker that has been investigated in sepsis is interleukin-6 (IL-6), which is released in response to tissue injury or an inflammatory stimulus [33] and the magnitude of its elevation correlates with the extent of tissue trauma/injury severity [34]. The blood IL-6 levels are elevated in patients with sepsis and septic shock [35, 36], correlate with disease severity [35-37], and possibly predict unfavorable outcome [36]. Moreover, IL-6 could be a faster indicator of treatment success in adults with severe sepsis and septic shock compared to PCT and CRP [37]; however, some studies found no additive effect for IL-6 in the diagnosis of the severe infection in critically ill patients [38]. In a recently published systematic review regarding biomarkers of sepsis, Pierrakos et al. indicated that IL- 6 in comparison with PCT and/or CRP for sepsis diagnosis provided conflicting findings and that so far IL-6 was not evaluated for prognostic value in large clinical studies [39]. Given the above, more data from comprehensive clinical studies are needed to properly evaluate the utility of IL-6 in everyday clinical practice. Following such approach bedside or point of care tests for measurement of IL-6 are being developed and validated [40]. It is possible that enhanced accessibility of the method, together with a short time to result and low costs would enable broader clinical usage and evaluation of IL-6.

Our study has several limitations. First, the implementation of PCT-guided stewardship is only moderate, which might be explained by failure to strictly follow the algorithms available in the scientific literature. The antibiotic treatment was discontinued for 7 patients and modified for 29 patients according to the PCT results. It seems that termination of antibiotic therapy in seven patients did not harm the patients since there was no recorded reinfection or other adverse effects. Moreover, the application of PCT-guided stewardship led to shorter ICU LOS which might lead to the reduction of healthcare costs; however, the number of patients is too low to show statistical significance. The second limitation pertains to the patient case-mix. The presented population of patients is quite heterogeneous. While this diversity reflects everyday reality in the medical ICU, it may cause inaccurate interpretation of patient subgroups.

To conclude, this study shows that PCT can be used as an additional marker of disease severity in critically ill patients. Increased initial PCT levels might point to the development of more severe disease caused by Gram-negative bacteria and PCT might be considered as a valuable marker of infection in patients who were pretreated with antibiotics. This pertains to immunocompetent as well as immunocompromised patients. Implementation of PCT-guided stewardship should be encouraged and will probably increase with gaining further experience in clinical interpretation of novel routine biomarkers in the decision-making process.

Acknowledgements We thank Ozrenka Zlopaša, Nina Gubarev Vrdoljak and Luka Bielen for their continuous support. 


\section{Compliance with ethical guidelines}

Conflict of interest A. Vujaklija Brajković, I. Košuta, D. Tomek, M. Rora, J. Babel, D. Rogić, A. Lončar Vrančić, and R. Radonić declare that they have no competing interests.

Ethical standards The Ethics Committee of the University Hospital Centre Zagreb approved this research as a non-sponsored prospective epidemiological study. Considering the design of the study and possible exceptions to the rule of informed consent, the informed consent was waived for the present study.

\section{References}

1. Kumar A, Roberts D, Wood KE, Light B, Parrillo JE, Sharma S, et al. Duration of hypotension before initiation of effective antimicrobial therapy is the critical determinant of survival in human septic shock. Crit Care Med. 2006;34(6):1589-96.

2. Fridkin S, Baggs J, Fagan R, Magill S, Pollack LA, Malpiedi P, et al. Vital signs: improving antibiotic use among hospitalized patients. Mmwr Morb Mortal Wkly Rep. 2014;63(9):194-200.

3. Bouadma L, Luyt C-E, Tubach F, Cracco C, Alvarez A, Schwebel C, et al. Use of procalcitonin to reduce patients' exposure to antibiotics in intensive care units (PRORATA trial): a multicentre randomised controlled trial. Lancet. 2010;375(9713):463-74.

4. Jensen JU, Hein L, Lundgren B, Bestle MH, Mohr TT, Andersen $\mathrm{MH}$, et al. Procalcitonin-guided interventions against infections to increase early appropriate antibiotics and improve survival in the intensive care unit: a randomized trial. Crit Care Med. 2011;39(9):2048-58.

5. Assink-de Jong E, de Lange DW, van Oers JA, Nijsten MW, Twisk JW, Beishuizen A. Stop antibiotics on guidance of procalcitonin study (SAPS): a randomised prospective multicenter investigator-initiated trial to analyse whether daily measurements of procalcitonin versus a standard-of-care approach can safely shorten antibiotic durationinintensive care unit patients-calculated sample size: 1816 patients. BMCInfect Dis. 2013;13:178.

6. Schroeder S, Hochreiter M, Koehler T, Schweiger A-M, Bein B, KeckFS, et al. Procalcitonin (PCT)-guided algorithm reduces length of antibiotic treatment in surgical intensive care patients with severe sepsis: results of a prospectiverandomized study. Langenbecks Arch Surg. 2009;394(2):221-6.

7. Hohn A, Schroeder S, Gehrt A, Bernhardt K, Bein B, Wegscheider K, et al. Procalcitonin-guided algorithm to reduce length of antibiotic therapy in patients with severe sepsis and septic shock. BMC Infect Dis. 2013;13:158.

8. Nobre V, Harbarth S, Graf J-D, Rohner P, Pugin J. Use of procalcitonin to shorten antibiotic treatment duration in septic patients: a randomized trial. Am J Respir Crit Care Med. 2008;177(5):498-505.

9. Stolz D, Smyrnios N, Eggimann P, Pargger H, Thakkar N, Siegemund M, et al. Procalcitonin for reduced antibiotic exposure in ventilator-associated pneumonia: a randomised study. Eur Respir J.2009;34(6):1364-75.

10. Layios N, Lambermont B, Canivet J-L, Morimont P, Preiser J-C, Garweg C, et al. Procalcitonin usefulness for the initiation of antibiotic treatment in intensive care unit patients. Crit Care Med. 2012;40(8):2304-9.

11. Oliveira CF, Botoni FA, Oliveira CRA, Silva CB, Pereira HA, Serufo JC, et al. Procalcitonin versus C-reactive protein for guiding antibiotic therapy in sepsis: a randomized trial. Crit Care Med. 2013;41(10):2336-43.
12. Deliberato RO, Marra AR, Sanches PR, Martino MDV, dos Santos Ferreira CE, Pasternak J, et al. Clinical and economic impact of procalcitonin to shorten antimicrobial therapy in septic patients with proven bacterial infection in an intensive care setting. Diagn Microbiol Infect Dis. 2013;76(3):266-71.

13. Shehabi Y, Sterba M, Garrett PM, Rachakonda KS, Stephens D, Harrigan P, et al. Procalcitonin algorithm in critically ill adults with undifferentiated infection or suspected sepsis. A randomized controlled trial. Am J RespirCritCare Med. 2014;190(10):1102-10.

14. Bloos F, Trips E, Nierhaus A, Briegel J, Heyland DK, Jaschinski U, et al. Effect of sodium selenite administration and procalcitonin-guided therapy on mortality in patients with severe sepsis or septic shock: a randomized clinical trial. JAMAIntern Med. 2016;176(9):1266-76.

15. AnnaneD, MaximeV,FallerJP, MezherC,Clec'hC, MartelP, et al. Procalcitonin levels to guide antibiotic therapy in adults with non-microbiologically proven apparent severe sepsis: a randomised controlled trial. BMJ Open. 2013;3(2):e2186. https://doi.org/10.1136/bmjopen-2012-002186.

16. Huang H-B, Peng J-M, Weng L, Wang C-Y, Jiang W, Du B. Procalcitonin-guided antibiotic therapy in intensive care unit patients: a systematic review and meta-analysis. Ann Intensive Care. 2017;7(1):114.

17. Wirz Y, Meier MA, Bouadma L, Luyt CE, Wolff M, Chastre J, et al. Effect of procalcitonin-guided antibiotic treatment on clinical outcomes in intensive care unit patients with infection and sepsis patients: a patient-level meta-analysis of randomized trials. Crit Care. 2018;22(1):191.

18. Schuetz P, Beishuizen A, Broyles M, Ferrer R, Gavazzi G, GluckEH, etal. Procalcitonin (PCT)-guided antibioticstewardship: an international experts consensus on optimized clinical use. Clin Chem Lab Med. 2019;57(9):1308-18.

19. Aguilar-Guisado M, Espigado I, Martín-Peña A, Gudiol C, Royo-Cebrecos C, Falantes J, et al. Optimisation of empirical antimicrobial therapy in patients with haematological malignancies and febrile neutropenia (how long study): an open-label, randomised, controlled phase 4 trial. Lancet Haematol. 2017;4(12):e573-83.

20. Singer M, Deutschman CS, Seymour CW, Shankar-Hari M, Annane D, Bauer M, et al. The third international consensus definitions for sepsis and septic shock (sepsis-3). JAMA. 2016;315(8):801-10.

21. KDIGO. KDIGO clinical practice guideline for acute kidney injury. Kidney IntSuppl. 2012;2:1-138.

22. Knaus WA, Draper EA, Wagner DP, Zimmerman JE. APACHE II: a severity of disease classification system. Crit Care Med. 1985;13(10):818-29.

23. Vincent JL, de MendonçaA, Cantraine F, Moreno R, Takala J, Suter PM, et al. Use of the SOFA score to assess the incidence of organ dysfunction/failure in intensive care units: results of a multicenter, prospective study. Working group on "sepsis-related problems" of the European society of intensive care medicine. Crit Care Med. 1998;26(11):1793-800.

24. Schuetz P, Albrich W, Mueller B. Procalcitonin for diagnosis of infection and guide to antibiotic decisions: past, present and future. BMCMed. 2011;9:107.

25. Lapić I, Rogić D, Fuček M, Galović R. Effectiveness of minimum retesting intervals in managing repetitive laboratory testing: experience from a Croatian university hospital. Biochem Med. 2019;29(3):30705.

26. Rebers S, Aaronson NK, van Leeuwen FE, Schmidt MK. Exceptions to the rule of informed consent for research with an intervention. BMCMed Ethics. 2016;17:9.

27. Meisner M. Update on procalcitonin measurements. Ann Lab Med. 2014;34(4):263-73. 
28. Reinhart K, Karzai W, Meisner M. Procalcitonin as a marker of the systemic inflammatory response to infection. Intensive Care Med. 2000;26(9):1193-200.

29. Rhee C. Using procalcitonin to guide antibiotic therapy. Open Forum Infect Dis. 2017;4(1):ofw249.

30. Li S, Rong H, Guo Q, Chen Y, Zhang G, Yang J. Serum procalcitonin levels distinguish Gram-negative bacterial sepsis from Gram-positive bacterial and fungal sepsis. J Res Med Sci. 2016;21:39.

31. Luo X, Chen S, Zhang J, Ren J, Chen M, Lin K, et al. Procalcitonin as a marker of Gram-negative bloodstream infections in hematological patients with febrile neutropenia. Leuk Lymphoma. 2019;60(10):2441-8.

32. Andriolo BN, Andriolo RB, Salomão R, Atallah ÁN. Effectiveness and safety of procalcitonin evaluation for reducing mortality in adults with sepsis, severe sepsis or septic shock. Cochrane Database Syst Rev. 2017;1:CD10959.

33. Jawa RS, Anillo S, Huntoon K, Baumann H, Kulaylat M. Analytic review: interleukin-6 in surgery, trauma, and critical care: part I: basic science. J Intensive Care Med. 2011;26(1):3-12.

34. Jawa RS, Anillo S, Huntoon K, Baumann H, Kulaylat M. Interleukin-6 in surgery, trauma, and critical care part II: clinical implications. J Intensive Care Med. 2011;26(2):73-87.

35. JekarlDW, KimJY, LeeS, Kim M, KimY,HanK, etal. Diagnosis and evaluation of severity of sepsis via the use of biomarkers and profiles of 13 cytokines: a multiplexanalysis. Clin Chem Lab Med. 2015;53(4):575-81.

36. Oda S, Hirasawa $H$, Shiga $H$, Nakanishi K, Matsuda $K$, Nakamua M. Sequential measurement of IL-6 blood levels in patients with systemic inflammatory response syndrome (SIRS)/sepsis. Cytokine. 2005;29(4):169-75.

37. Weidhase L, Wellhöfer D, Schulze G, Kaiser T, Drogies T, Wurst U, et al. Is interleukin-6 a better predictor of successfulantibiotic therapythan procalcitonin andC-reactive protein? A single center study in critically ill adults. BMC Infect Dis. 2019;19(1):150.

38. Harbarth S, Holeckova K, Froidevaux C, Pittet D, Ricou B, Grau GE, et al. Diagnostic value of procalcitonin, interleukin-6, and interleukin-8 in critically ill patients admitted with suspected sepsis. Am J Respir Crit Care Med. 2001;164(3):396-402.

39. Pierrakos C, Velissaris D, Bisdorff M, Marshall JC, Vincent J-L. Biomarkers of sepsis: time for a reappraisal. Crit Care. 2020;24(1):287.

40. Fischer SK, Williams K, Wang L, Capio E, Briman M. Development of an IL-6 point-of-care assay: utility for real-time monitoring and management of cytokine release syndrome and sepsis. Bioanalysis. 2019;11(19):1777-85.

Publisher's Note Springer Nature remains neutral with regard to jurisdictional claims in published maps and institutional affiliations. 